\section{ECONOMICS}

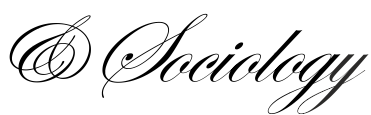

Flessa, S., \& Meissner, K. (2019). Sustainability of health systems research conceptional framework based on two projects. Economics and Sociology, 12(3), 220 235. doi:10.14254/2071-789X.2019/12-3/15

\title{
SUSTAINABILITY OF HEALTH SYSTEMS RESEARCH - A CONCEPTIONAL FRAMEWORK BASED ON TWO PROJECTS
}

\author{
Steffen Flessa, \\ Department of Health Care \\ Management, \\ University of Greifswald, \\ Germany \\ E-mail:Steffen.flessa@t-online.de
}

\section{Konrad Meissner, \\ Department of Anesthesiology, University Hospital of Greifswald, Germany \\ E-mail:konrad.meissner@uni- greifswald.de}

Received: February, 2019

1st Revision: May, 2019

Accepted: August, 2019

DOI: $10.14254 / 2071-$

789X.2019/12-3/15

JEL Classification: I11, I18
ABSTRACT. 1) Background: Projects of health systems research frequently suffer from poor sustainability, i.e., the innovations generated in the project are not adopted as standards. As soon as project funding ends, the interest of researchers declines and the innovations will not make their way in the routine health care system. This failure is partly due to the fact that key partners of the project are very good researchers, but sustainability is not in the core of their interest. Only a few researchers are promoting the adoption of the project innovations in the routine system. 2) Methods: Based on the experience of two major research projects (GANI_MED, InGRiP) we developed a stakeholder-typology of research projects as a conceptional framework. For GANI_MED we distinguish the dimensions "relevance" and "identification", for InGRiP the dimensions "innovativeness" and "deployment". 3) Findings: The methodology was applied on two health systems research projects demonstrating its feasibility and applicability. 4) Conclusions: We conclude that the sustainability of research projects requires that this objective is a key concern of all partners from the very beginning. It will not just happen but has to be planned, promoters must be fostered and roles must be clearly defined.

Keywords: Change management, GANI_MED, InGRiP, Innovation, German health care system

\section{Introduction}

Sustainability has become a buzzword of the research community. In particular health economics and health systems research is always required to indicate that the project will be sustained after the end of the funding period, and scaling-up (i.e. expanding beyond the limited scale of the pilot towards the entire region or system) is frequently expected. In principle, a project is defined by limited scope and duration (Turner 2014), but every funding agency - be it EU, federal ministries or foundations - calls for a proof that the content of the project will be functional for a very long time and beyond the limitations of the pilot area. In particular, in the health care system sustainability is frequently seen as the new magic stick - although it is hardly defined and usually everybody has a different concept of what "sustainable" actually means (Imison, Naylor et al. 2011, Haseltine 2013). 
The term sustainability was originally used in forestry (Fleßa 2002). During the middle ages, the Central European forests had been so degraded that the rulers of that time had to pass laws against the over-use of woodlands. It became a rule that the annual cut must not exceed the annual growth of wood in a forest. This was called "sustainable" as future generations would find the same quantity and quality of forests as the present generation.

The term entered international politics in 1972 during the UN Conference on environment and development in Stockholm which ended in a severe conflict between the interests of developed and developing countries: The latter insisted in their right on development, whereas the western world demanded more environmental protection. The solution for this goal conflict was "sustainable development". Later conferences and reports, such as the Brundtland-Report (1987), the UN Conference on Environment and Development in Rio de Janeiro (1992), the Khartoum-Declaration (1988) and the Lusaka-Declaration (1999), developed the concept further (Kuhlman and Farrington 2010). Today, it covers economic, social and ecological dimensions with the following essentials:

- Inter-generational justice: future generations should have the same access to resources as the present generation. This is the traditional meaning of the term as it was derived from agriculture and forestry (Thurston 1997, Buck, Lassoie et al. 1998). However, the concept of inter-generational justice is frequently applied on many other systems such as health care calling for a "future ethics" (Jonas 1984) with a strong focus on maintaining systems beyond this generation.

- Development vs. growth: the majority of economic theories analyze the economic growth by an increase of gross national product. This incorporates that a nation can increase its economic growth by selling natural resources beyond their ability to regenerate. The concept of development stresses more the complexity of a system, i.e. the number of elements and their relation. This would mean that a nation that destroys its natural resources reduces its own complexity and, thus, induces negative development. The concept of sustainability calls for development instead of purely quantitative growth.

- Intra-generational justice: sustainable development includes solidarity between the rich and the poor, i.e., resources should be distributed equally.

Consequently, the Brundtland Report defines sustainable development as "development that meets the needs of the present without compromising the ability of future generations to meet their own needs" (Brundtland 1987). In the last twenty years, the concept of sustainability has entered other fields of economics. We talk about "sustainable programs", "sustainable projects" or "sustainable institutions" and most funding agencies demand that projects and institutions that they support should be sustainable. In all cases, sustainability somehow considers the needs of future systems or populations even if the "inter-generational justice" could mean only "beyond the end of the project" or within a few years. However, even within this framework of extending sustainability beyond natural resources, a number of different concepts are used simultaneously without a proper definition. For instance, a health systems research project can be unsustainable because

- it cannot survive without the funding of the project,

- it might survive without funding, but the rules and regulations do not allow the project to become more than just another pilot,

- it might survive in the project area for a long time, but it does not spread beyond the borders of this area,

- it might survive as long as no major changes in the environment happen, but the system has no capacity to adapt to changes in the environment.

It is obvious, that different concepts of sustainability stand behind these four causes of poor sustainability. This requires a proper definition. 
In this paper, sustainability is defined as the ability of a system to provide services in the present without sacrificing the provision of services in the future. A system can always be defined by its function and structures, i.e., the function of the system in its environment is the transformation of input into output while its structure (elements and relations) is suited to combine the inputs in such a way that results are produced which add value to the environment. Based on the distinction between structures and functions as well as between dynamic and static systems we can distinguish concepts of sustainability (Olsen 1998, pp. 287-295):

- Static vs. dynamic sustainability: the term "static sustainable" should be used if a system can perpetually survive in its constant environment. On the contrary, the term "dynamic sustainable" should be applied if a system is able to react to changes in the environment so that it can survive under changed conditions. A system can exist forever under unchanging conditions, but it might be rapidly destroyed as soon as these conditions are modified.

- Functional vs. structural sustainability: a system is called "functional sustainable" if it is able to keep up with the production of a worthwhile output. If the system is able to maintain its structure (elements and relations) it is called "structural sustainable".

As

Table 1 shows, these categories form a matrix with four elements (Fleßa 2002). Table 2 shows the concept of sustainability applied to health systems projects. A project is static functional sustainable, if the structures remain intact after the end of the project under the assumption, that no major changes occur. For instance, if the project includes the development of a cross-border emergency system, static functional sustainability could mean that the shared emergency number, the rules of transport and the emergency cars are still in use after the end of the project. Functional static sustainability, however, could mean that cross-border health care remains a core focus of the emergency services on both sides of the border under the condition that no major system changes will occur. The structures might change (e.g. emergency number), but the function (cross-border emergency care) is still fulfilled.

Dynamic sustainability assumes that major changes in the economic, social, demographic, technical or legal environment will change. For instance, changes in laws or new technologies might challenge the existing cross-border emergency care systems. Dynamic structural sustainability would mean that these innovations are adopted by the existing structure. For instance, if a law were introduced permitting cross-border helicopter emergency services, the existing services will add this service to their portfolio within the existing structures. Dynamic functional sustainability goes even beyond that, i.e., cross-border emergency care is constantly developed, innovations are adopted and the structure adapted. For instance, the emergency care systems on both sides of the border might fuse completely and make crossborder systems irrelevant.

Table 1. General concept of sustainability

\begin{tabular}{lcc}
\hline & \multicolumn{1}{c}{ Structural } & Functional \\
\hline Static & static functional sustainable & static structural sustainable \\
\hline Dynamic & dynamic functional sustainable & dynamic structural sustainable \\
\hline
\end{tabular}

Dynamic sustainability requires that innovations are adopted by the existing system to become a permanent standard. As Figure 1 shows, the process of adopting an innovation to become a sustainable standard is a complex process requiring the existence of promoters. Only if the old system performs poorly (functionality of old system), if the innovation costs are low, the personal interest of stakeholders are high, the complexity of the innovation is low and the inclination of the promotors to innovations is high, the innovation which is developed during the project has a chance to be sustained afterward. Consequently, the existence and the personal 
commitment of promotors is crucial for the sustainability of research projects beyond the pilot phase.

Table 2. Concept of sustainability applied to Health Systems Projects

\begin{tabular}{lll}
\hline & \multicolumn{1}{c}{ Structural } & \multicolumn{1}{c}{ Functional } \\
\hline Static & $\begin{array}{l}\text { Structures remain after the end of the } \\
\text { project if nothing else happens. }\end{array}$ & $\begin{array}{l}\text { Cross-border health care remains a core } \\
\text { focus of the emergency services on both } \\
\text { sides of the border if nothing else } \\
\text { changes. }\end{array}$ \\
\hline Dynamic & $\begin{array}{l}\text { Innovations (e.g. new methods of cross- } \\
\text { border health care) are adopted by the } \\
\text { existing InGRiP-structure. }\end{array}$ & $\begin{array}{l}\text { Cross-border emergency care is constantly } \\
\text { developed, innovations are adopted and } \\
\text { the structure adapted. }\end{array}$ \\
\hline
\end{tabular}

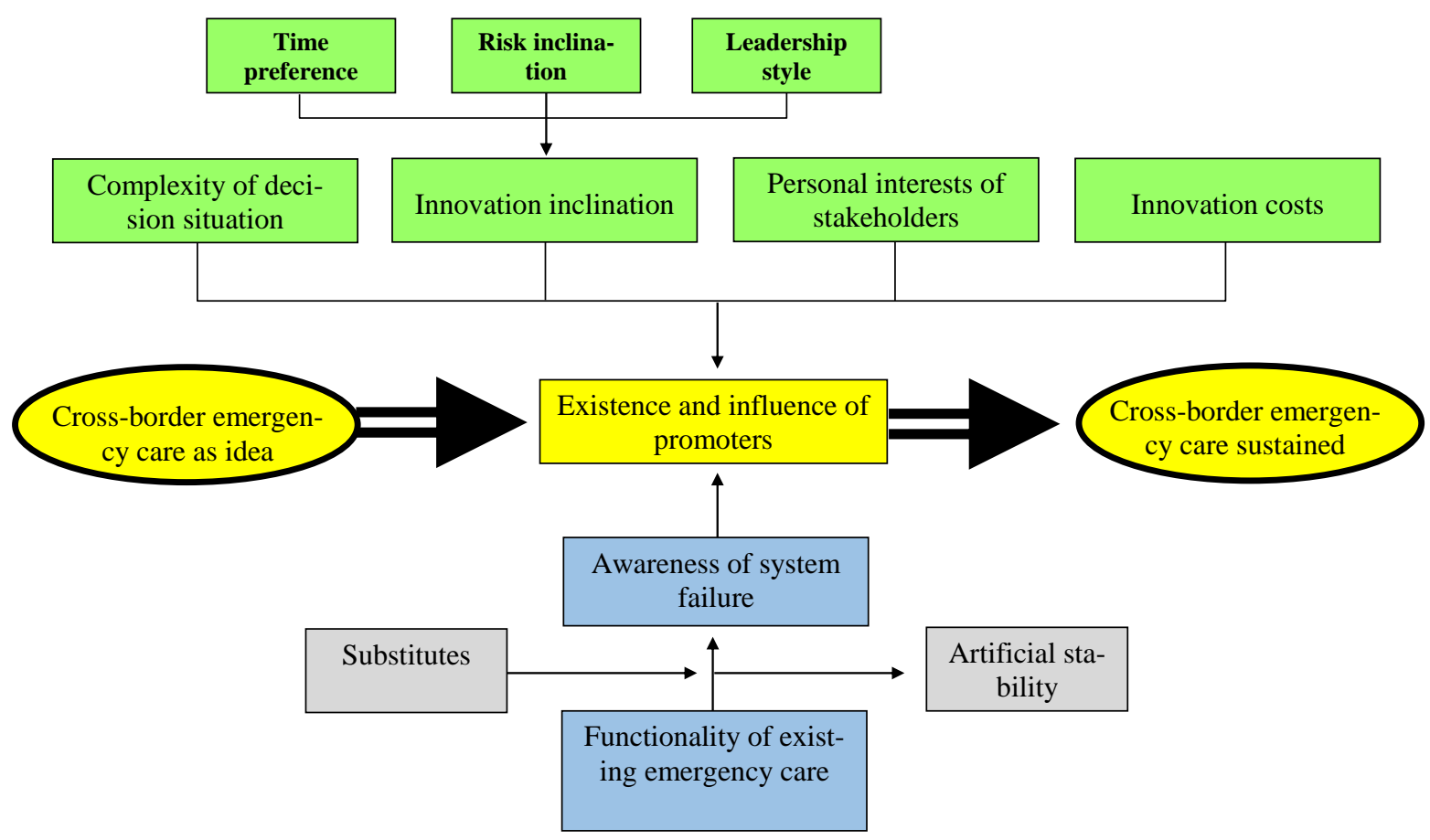

Figure 1. Process of Adopting Innovations; here: cross-border emergency care (Fleßa 2018)

In the following, we will analyze the roles of promotors of research projects for the sustainability of health systems research projects in order to extract a conceptional framework of different partners of research projects which allows to analyse their role and develop norm strategies for each role. For this purpose, the next section presents two publicly funded research projects (GANI_MED, InGRiP) which resulted in innovations. Afterward, we will present the methodology to analyze the role of stakeholders in this process. The results will be presented in the fourth section. The paper closes with a discussion of the results and sets the reference to future research projects. 


\section{Case Studies}

\subsection{GANI_MED}

The "Greifswald Approach to Individualized Medicine" (GANI_MED) was a research project funded by the Federal Ministry of Education and Research of Germany and the State of Mecklenburg-Western Pomerania from October 2009 to September 2014 with a budget of 15 million Euro. The main objective was to establish "individualized medicine" (IM) as a new standard of medical research and treatment at the university hospital of Greifswald and some partner institutions. Individualized Medicine, Personalized Medicine, Precision Medicine, and Systems Medicine are closely related concepts, and it is difficult to define and differentiate them (Schleidgen \& Marckmann 2013). Schleidgen et al. conclude that it "seeks to improve tailoring and timing of preventive and therapeutic measures by utilizing biological information and biomarkers on the level of molecular disease pathways, genetics, proteomics as well as metabolomics."(Schleidgen, Klingler et al. 2013)

The project combined experts from five faculties and provided an infrastructure (e.g. bio-bank) to "systematically develop innovative analytical procedures that allow new insights into individual differences during the formation, progression and treatment of medically and societally relevant disease conditions, including heart disease, stroke, renal failure, fatty liver, periodontal disease and the metabolic syndrome. To this end, several patient cohorts [were] established [...]" (http://www2.medizin.uni-greifswald.de/gani_med/index.php?id= $606 \& \mathrm{~L}=1$ ). The final objective was to integrate clinical and population-based research and "to ascertain whether and which promising individualization concepts are suited for the treatment of patients". The proposal of GANI_MED promised that the concept would be sustained beyond the end of the project.

Four years after the project has ended, we can conclude:

1) The structures of GANI_MED are still in use, e.g., the bio-bank is fully functional, the cohort database is still maintained and the clearing agency still exists (structural static sustainability),

2) The functions of GANI_MED are maintained, e.g., the materials of the bio-bank and data of the cohorts are used for further studies (functional static sustainability),

3) A core team of former members of the GANI_MED-project meets regularly to discuss how to maintain the structures of GANI_MED under new conditions (e.g. changed financing, change of leaders etc.) (structural dynamic sustainability),

4) A core team of former members of the GANI-MED project attempts to transfer scientific results from GANI_MED into routine patient care, i.e. in a completely new scientific realm and under strongly changed conditions (dynamic functional sustainability).

One can state that the degree of sustainability declines from 1) to 4), i.e., aspects of the structural static sustainability are achieved to a higher degree than of the dynamic functional sustainability, but in principle the sustainability of the project is amazingly high: equipment is still in use and maintained, databases are utilized and up-kept, research project based on GANI_MED are submitted and executed, and innovative concepts of patient care are implemented (Fleßa, Thum et al. 2016). This leads to the question why GANI_MED is sustainable, while many other projects are not. The key to the answer is the existence of promoters, which will be analyzed in section 3 . 


\subsection{InGRiP}

The project InGRiP (,Integrierter grenzüberschreitender Rettungsdienst Pomerania/Brandenburg") intents to establish and analyze a system of cross-border emergency care between Poland and Germany (in the states of Mecklenburg-Western Pomerania and Brandenburg) in the period of November 2017 to October 2020. It is co-financed by the EU (EFRE) with a total budget of 2.3 million Euro. The most important modules are (1) the analysis of the legal situation and conditions of synchronizing emergency services in the two countries, (2) professional inter-cultural communication, (3) development of the infrastructure of air-born rescue and (4) simulation training. For instance, module (2) develops and conducts language training on both sides of the border, i.e., rescue assistants in Germany learn the professional rescue terminology in Polish, while the Polish rescue specialists learn communicating with German patients in their mother tongue.

As the project started in 2017, no conclusive analysis to assess the long-term sustainability of the InGRiP-innovations is possible. However, the project write-up makes it clear that this project will only be called successful if

1) developed structures (e.g. language training, emergency numbers, joint simulation training) are maintained within the region (structural static sustainability),

2) functions of cross-border emergency care will continue to be fulfilled within the region (functional static sustainability),

3) laws will be developed and funding provided by health financing mechanisms to safeguard continuation in the region and spread beyond (structural dynamic sustainability),

4) key stakeholders of cross-border emergency care will continue with their cooperation and seek to overcome barriers of optimal emergency care beyond the scope of InGRiP and even under changing conditions (e.g. political atmosphere between Poland and Germany).

Again, the level of complexity increases from 1) to 4) and leads to different outcomes. While 1) is clearly a must of the project outcome, 4) is a vision. InGRiP is one of the few projects defining clearly their sustainability objectives at the beginning of the project.

As stated above, the existence and motivation of promoters are crucial to sustaining a project beyond the funding phase. In this paper, we will analyze whether such promoters exist in GANI_MED and InGRiP and how this will affect the sustainability of the projects.

\section{Methods}

Based on the innovation adoption model presented in Figure 1, we developed a stakeholder typology for GANI_MED and InGRiP. The main objective is to determine types of project partners who are likely to become promoters of the adoption process from pilot innovation to standard application described in Figure 1. The typologies for both projects will differ because the first project is already finished while the second one has not even completed half of the project time.

The concept from GANI_MED was presented by Fleßa et al. in 2011 (Fleßa, John et al. 2011). As Figure 2 shows, the partners of a research project can be distinguished by two criteria, (1) the relevance of the partner for the performance of the project and (2) the identification with the project. Furthermore, the interviewer records the number and intensity of relations between the partners. Consequently, we receive a matrix with four different types of stakeholders in a research project:

1. Stars: Stars fully support the project idea and are highly relevant for the project success. They become leaders within the network and build relations with all existing and 
potential partners. It is crucial that stars remain aboard of the research project. A champion, i.e. a partner who is crucial to the success of the project, is usually a star.

2. Fighters: Fighters are not strongly committed to the objectives of the project, but they are highly relevant to the success of it. Fighters have only a few relations with other members of the project team. Frequently, they provide expertise (e.g. certain scientific techniques) which are without an alternative for the project, but they would not mind doing the same work with another project and other partners.

3. Good Buddies: These partners of a project are fully motivated by the project, but their influence on the project performance is limited. They build up many and intensive relations to other members of the project. They are trusted partners because they do not challenge others.

4. Predators: This type has little interest and little relevance to the project. Frequently, predators are added to a project because of political pressure. For instance, a project may only be accepted within a university if certain key players of that university are part of the project team, regardless of whether or not they can contribute to the objectives of the project. At the same time, predators might be added to the team of a multi-national proposal in order to fulfill the requirements of the funding agency, such as country- or gender balance. Thus, they are not added because they are relevant for the achievement of the objectives or because they are highly committed to this project, but because they are a prerequisite for the project to receive funding.

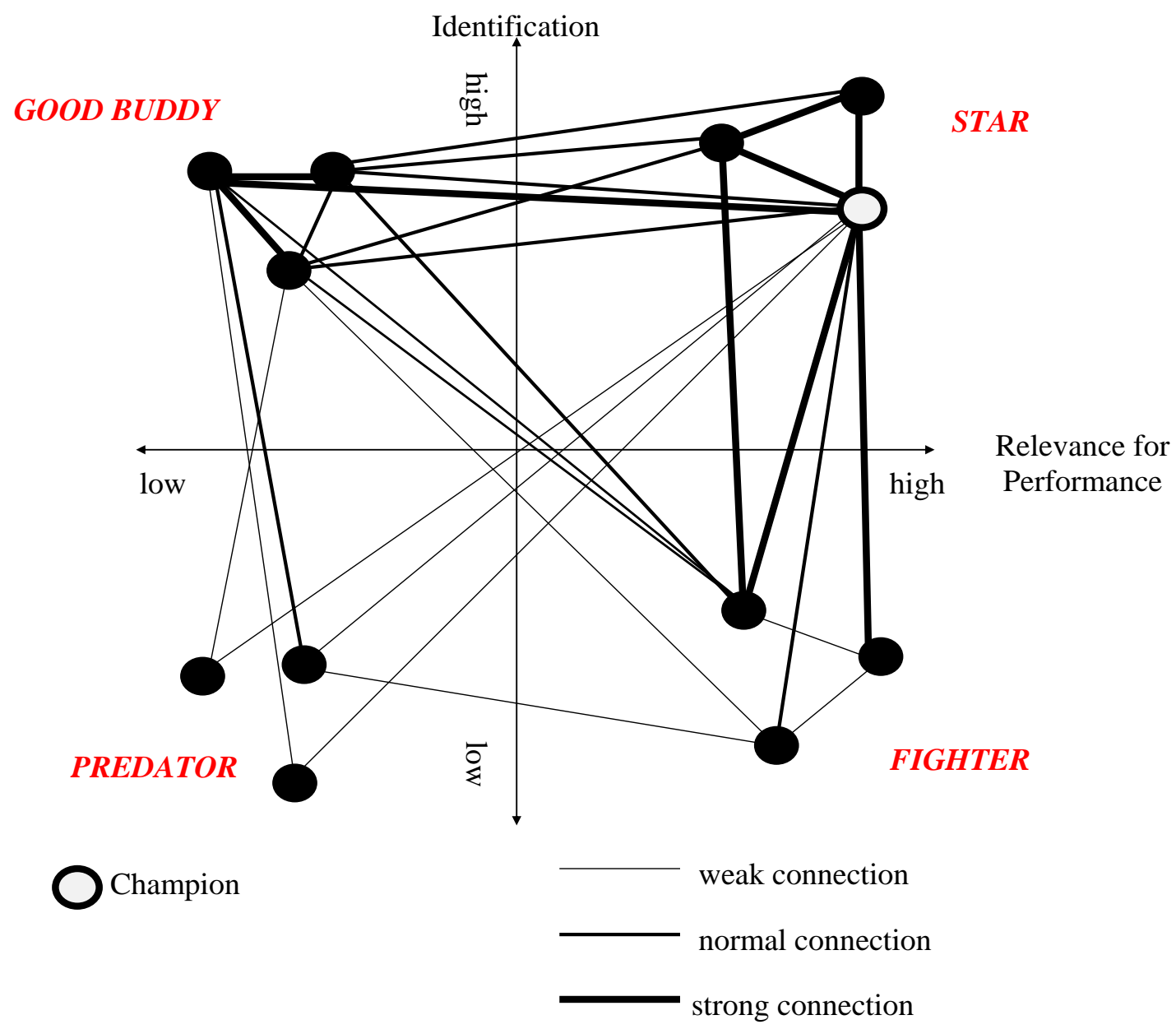

Figure 2. Stakeholder analysis GANI_MED - Principal dimensions (Fleßa, John et al. 2011) 
All project partners of GANI_MED (32) were interviewed twice at the beginning (2011) and towards the end of the project (2014) with the same interview guideline. Among other questions, the interviewers were asked to rate their own role in the consortium based on the dimensions (identification, relevance, relations) discussed above. The respective assessment and the dynamics will be presented in the next section.

The stakeholder analysis for InGRiP follows a similar methodology. However, as InGRiP just started, no ex-post-ex-ante comparison is possible. Consequently, other dimensions were selected in order to permit a thorough analysis of the sustainability of the project. As some partners are involved in different modules, we interviewed 17 stakeholders from 12 project partners in Poland and Germany and analyzed the number and intensiveness of relations. In addition, the innovativeness (defined as the creativity and acceptance of change), as well as the deployment (defined as long-term relevance for the system), are self-assessed by the partners. Here we differentiate:

1. Sparks: Sparks are partners of high creativity and innovativeness. They want to inspire others, change systems and have an impact. They write the proposal, connect with all others and motivate the team. During the research phase, they are highly relevant for the performance, but they do not maintain their high commitment beyond the project. After the funding ends, they will seek a new project, inspire another team and withdraw from the long-term implementation.

2. Stars: Stars have a long-term commitment and will sustain the project. They are highly innovative and willing to change the system even beyond the end of the project funding. They build long-term relations with all other members of the project. A champion, i.e. a person who is the key for the project to become a new standard, is usually a star.

3. Chocks: Chocks are of long-term relevance for the system. They will continue working in the same positions beyond the end of the project funding. However, as they are resistant to change, they might be hindering rapid implementation of the innovation as a standard. The higher the long-term relevance and the lower the innovativeness of a partner, the more likely he becomes a burden for the project.

4. Goiters: A goiter is a partner who is actually irrelevant for the long-term implementation of the project. At the same time, this partner is slow to change and averse of innovations. Goiters come aboard of projects due to political reasons. They might receive funding for modules that seem quite impressive but are not relevant to the project objectives. Instead, they use the project to continue with the work they have always done just predating on the additional funding. 
Innovativeness

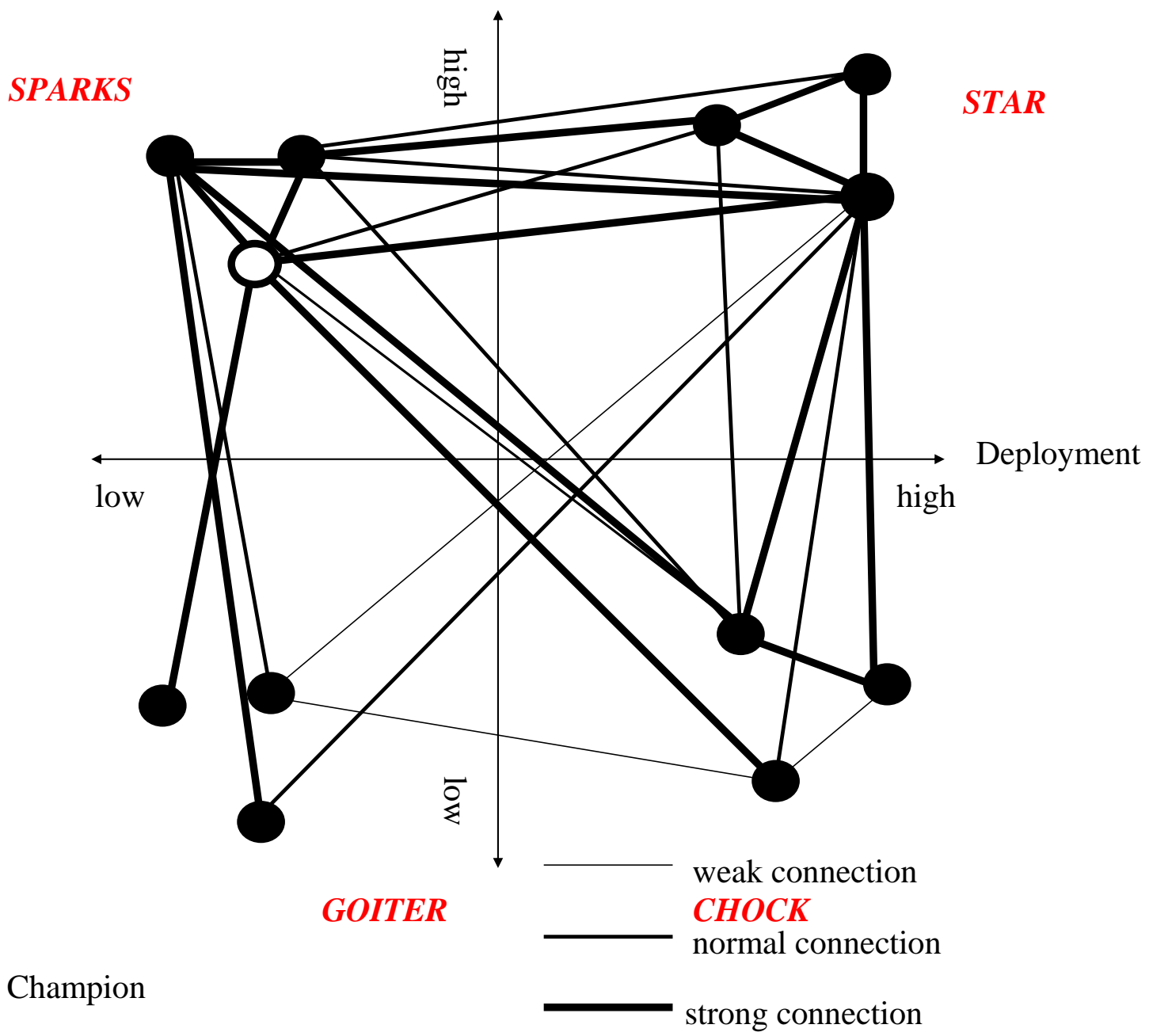

Figure 3. Stakeholder analysis InGRiP - Principal dimensions

As stated before, all partners of InGRiP were interviewed in order to determine their ability and willingness to become promoters of the transformation from the innovation idea of cross-border emergency care to the implementation as the new standard and long-term sustainability of the project results. The self-assessment in the dimension "deployment" was straightforward. The assessment of the dimension "innovativeness" was done by the interviewer based on the answers to the questions "Do you like changes generally in your private and professional life job?", "Do you like inspiring changes in your private and professional life?" as well as "Would you describe yourself as a person producing many ideas how to change emergency services?" The respective findings are presented in the next section.

\section{Results}

The majority of partners of GANI_MED assessed the project a success, which also contributed to the attractiveness of the respective university. However, the assessment of achieving objectives differed:

- Structural results:

- Biobank: Everybody assessed the development of the biobank for the cohorts as a great success. 
- Research database: The development of the research database was assessed as a great success by most interviewees.

- Leadership: The majority of interviewers stated that leadership had been great in the beginning, suffered from some problems in the middle of the project and become rather strong again towards the end.

- Cooperation: Almost all stated that the cooperation in particular between faculties had improved during the project.

- Functional results:

- Data utilization: The analysis of data gathered by GANI_MED was assessed as rather weak.

- A standard anamnesis had been developed and implemented.

- Proposals for ethical clearance are standardized.

- Very few publications were based on GANI_MED until 2014.

Based on the interviews we can state that the structural results of this project are strong, whereas the functional results are relatively weak. Consequently, we can expect that structural sustainability is higher than functional sustainability. The main weaknesses of the implementation were given as unclear structures and rules, weak leadership (at least for some time) and poor transparency of processes. In particular, different professions (e.g. medicine, theology, economics) have different cultures, which could not always be respected. Eventually, it was noticed that the willingness to continue cooperating was higher if the partners were in related fields (e.g. within medicine).

Figure 4 shows the results of the stakeholder typology of GANI_MED for 2014. At the beginning of the project, there was one champion. He initiated the project, connected all partners, was responsible for the proposal application and started everything. There were only a few stars, but quite a number of stakeholders in the other quadrants. Unfortunately, this star left the consortium after two years of challenging the success of the entire project. However, two fighters and one good buddy developed and became stars themselves. Thus, after four years there were more stars than before, but no champion. At the same time, the stars were highly connected with other partners, while predators had only weak connections with the others. It was obvious that they were useless for the implementation of the project, but had been included for the application process. The position and number of "good buddies" were almost unchanged. However, the majority of interview partners saw high relevance of them because they contributed social capital to the consortium and guaranteed smooth cooperation and emotional stability of the project.

GANI_MED continues to be a successful project as the loss of the champion was compensated by an increased number of stars. No star became a champion with a prime role, but closely connected stars took leadership responsibility for the consortium. This might be one reason why the project is still sustainable four years after the end of the funding period (as described above). The predators were lost right after the end of the projects, and the fighters jumped on other projects. However, good buddies and stars are cooperating to sustain the results of GANI_MED. This is particularly important as new legal, economic and medical challenges have come up requiring adjustment of procedures. The dynamic sustainability of the project could be safeguarded by a number of stars with the motivation and capability to promote the concept of individualized medicine within the structures of the university. 


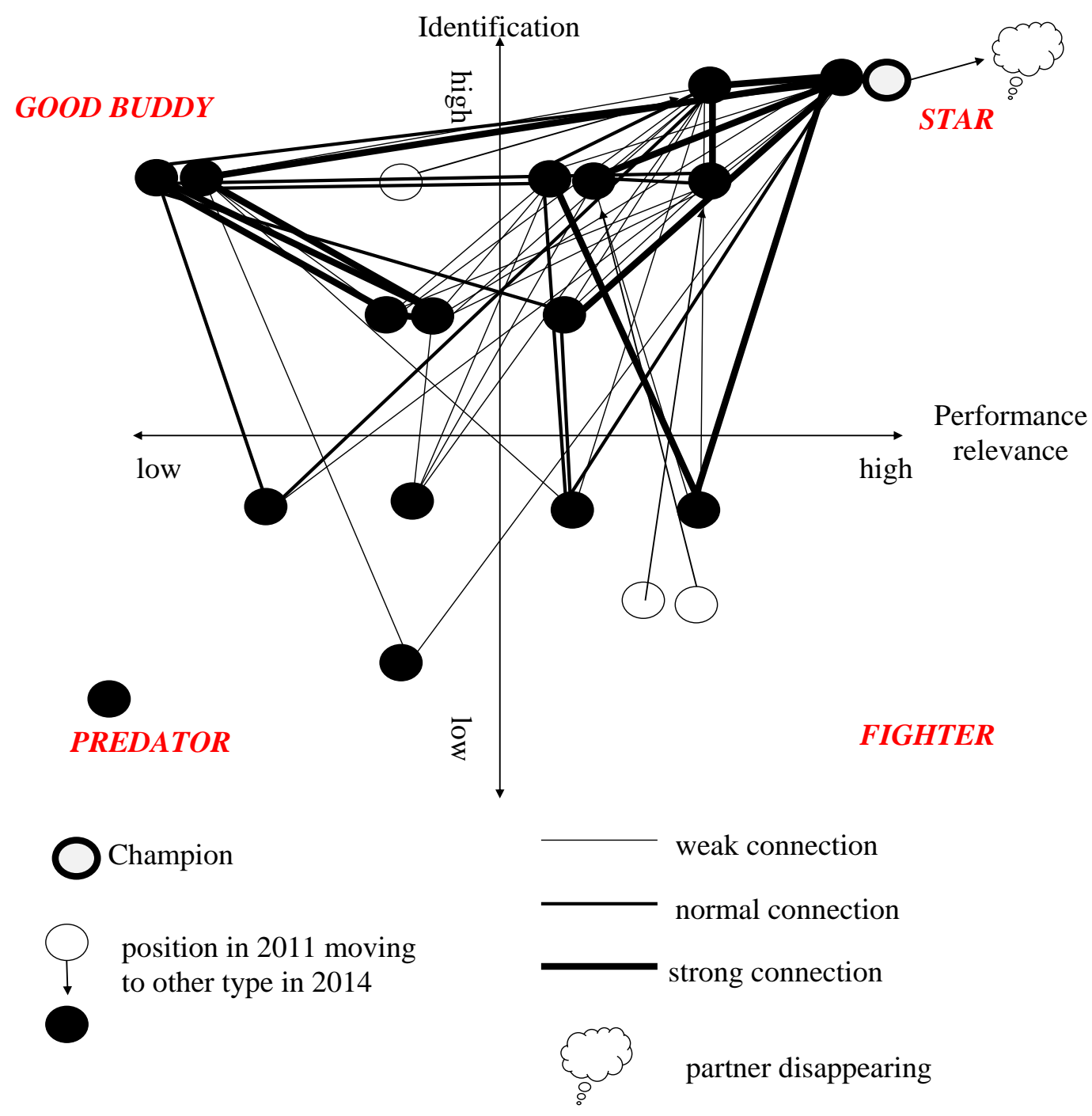

Figure 4. Stakeholder analysis GANI_MED - Results for 2014

The analysis of the InGRiP consortium also revealed that all four quadrants exist. One interview partner assessed the relevance of his module for the achievement of the objectives of the project as "average", but its long-term relevance is "rather weak". The same person assessed the creativity of its own institution as "very weak". This partner was categorized as goiter. Other interview partners distinguished between the modules of their responsibility. While all agreed that their institution will play a long-term role in the achievement of cross-border emergency care, they also agreed that some elements of the project were more relevant to get political consent and fit the conditions of the funding agency than to achieve long-term sustainability of cross-border health care. Assuming that a certain module of the project implements activity A, we asked the question: "Do you think that activity A must continue after the end of the project and be funded by external sources?" In addition to the goiter partner, researchers were mainly interested in analyzing the process of the pilot phase without prime interest what will happen afterward. These researchers are mainly "sparks" who are highly motivated to get the project run, to achieve the objectives and hand-over the routine to others.

The second set of questions analyzed the creativity and innovativeness of partners. Only a few stated clearly and straightforward that they would prefer if the old system of clear borders without cross-border emergency care persisted as it was much easier to manage administratively. However, some more interviewees were assessed as partners with low 
innovativeness based on how they judged the need to change, the required speed of change and the inclination to become change agents themselves.

Consequently, we find a number of sparks. The project was initiated by a scientist who acted like a champion. However, he will not be able to act as the prime mover after the project has ended. The routine implementation as a standard will have to be in the hands of a star or a set of stars. Fortunately, there are stars in the consortium, usually in the established emergency services on both sides of the border. They are willing and able to adopt the InGRiP innovations to become routine procedures.

The interviews revealed that there are also partners of InGRiP who are averse of changes and would prefer preserving the status-quo. The situation of cross-border emergency care is perceived as unsatisfactory, but these partners still prefer the current situation and try to avoid the risk and cumbersomeness of a system change. In some cases, they merely participated in the project because they were mainly interested in finding alternative ways of financing what they have been doing before or finance minor adaptions of the existing system. They preserve a meta-stable emergency system and try to keep changes to a minimum. As they are not really blocking changes of the other partners of InGRiP, they do not pose a problem to the sustainability and will fall out of the system as soon as the project ends.

Chocks, however, are relevant for the sustainability of the system. We found chocks in the public administration with a tendency to avoid change. Passing new laws and regulations, developing new institutions and adapting constantly to new challenges would be crucial for the municipal and district administrations, but the decision-makers also realize that this will mean a cascade of changes. Once regulations for cross-border emergency care are altered, intraterrestrial emergency care will have to be changed as well, which will have an impact on health care in general. Consequently, there is a group of InGRiP partners, which is likely to block changes and become a chock of sustainability.

As Figure 5 shows, there are a number of stars in the project who are strongly connected to the other partners. Consequently, the handover of leadership from the spark(s) to the stars could work smoothly and will safeguard that cross-border health care is sustained. It will, however, require to encourage, motivate and convince the chocks. It is positive that they are connected with the stars so that there is an entrance towards changing them to become stars themselves during the rest of the project.

Table 3 shows the factors of success and failure of the project and the long-term sustainability. It is obvious that the factors are not identical. While good cooperation and leadership are more prominent for the period until the end of the project, long-term financing becomes the most important success factor for long-term sustainability. Most interview partners referred to concepts of structural sustainability (e.g. legal frameworks, a continuation of activities) assuming that maintaining the structures (e.g. training) would also safeguard that the functions were fulfilled. At the same time, most interview partners focused on aspects of static sustainability (i.e. under the assumption that the framework is unchanged) while few referred to a dynamic concept, e.g. sustainability under changing political relationships between Poland and Germany. Summarizing, sustainability seems to be a burning issue in the project with a strong focus on financing and legal frameworks. 
Innovativeness

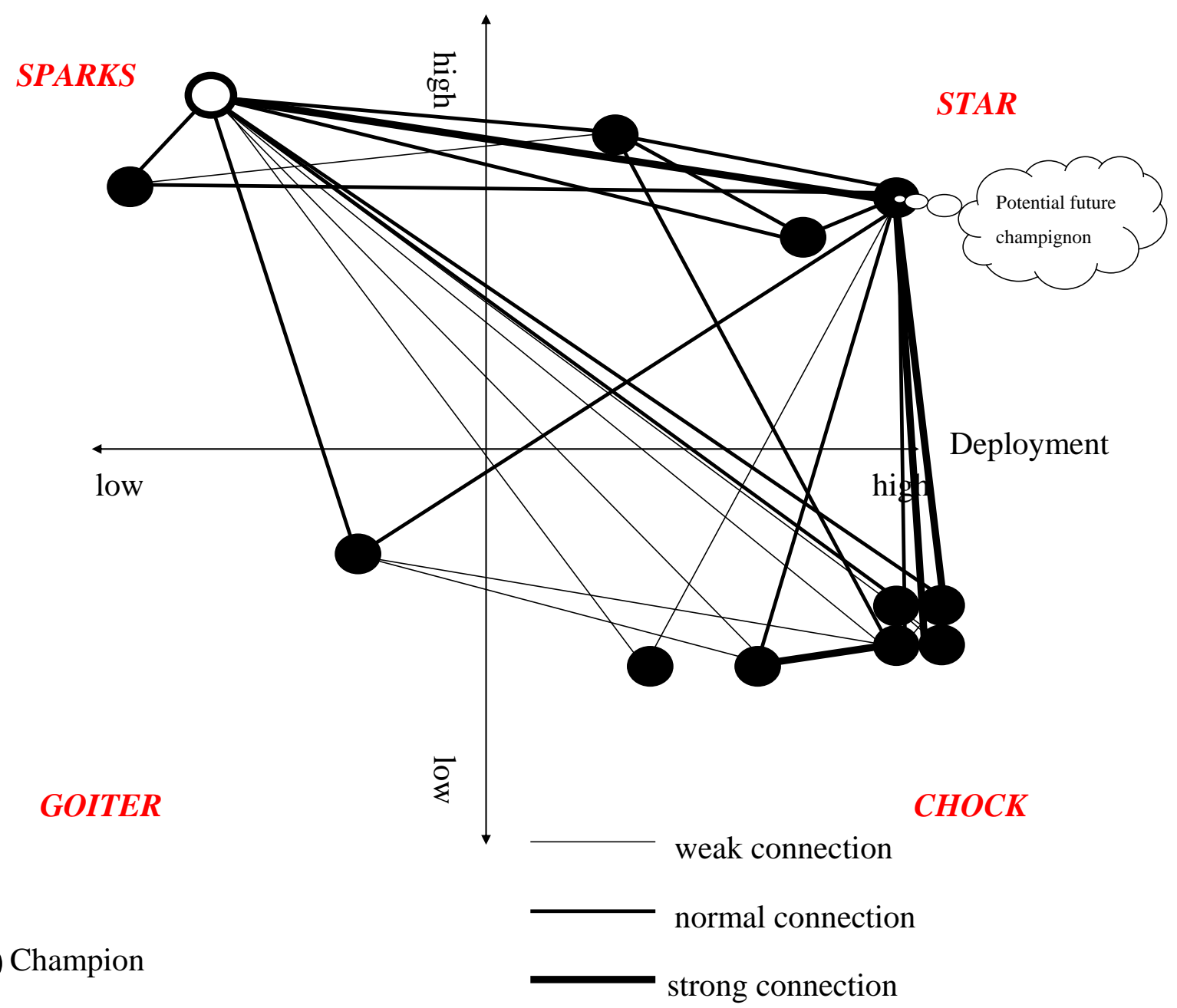

Figure 5. Stakeholder analysis InGRiP - Results for 2018

The table also demonstrates that factors or success and failure of scientific projects in the health care field are not very specific and overlap strongly with the general factors of success and failure of project management. Good cooperation, leadership and project management are crucial irrespective whether we talk about a health research or any other project.

Table 3. Success and Failure Factors until End of Project

\begin{tabular}{|c|c|c|}
\hline $\begin{array}{c}\text { Time } \\
\text { Horizon }\end{array}$ & Success Factors & Failure Factors \\
\hline \multirow[t]{4}{*}{$\begin{array}{l}\text { Success of } \\
\text { project }\end{array}$} & Good cooperation & $\begin{array}{l}\text { Poor cooperation } \\
\text { poor compromises }\end{array}$ \\
\hline & Strong leadership & $\begin{array}{l}\text { Unclear hierarchies and leadership } \\
\text { Loss of sparks and champignons }\end{array}$ \\
\hline & $\begin{array}{ll}\text { Professional } & \text { inter-cultural } \\
\text { communication } & \\
\text { knowledge of languages } & \\
\end{array}$ & $\begin{array}{l}\text { Language barriers } \\
\text { Inter-cultural differences } \\
\text { poor networking }\end{array}$ \\
\hline & $\begin{array}{l}\text { Mutual interest } \\
\text { Willingness to succeed } \\
\text { Many small activities of relevance }\end{array}$ & Unclear assignments \\
\hline
\end{tabular}




\begin{tabular}{|c|c|c|}
\hline & Fun and motivation & $\begin{array}{l}\text { Poor acceptance by practical rescue } \\
\text { workers } \\
\text { Staff turnover }\end{array}$ \\
\hline & & Rapid dislearning \\
\hline & Good documentation & Poor documentation \\
\hline & Political support & Political influences \\
\hline & $\begin{array}{llll}\begin{array}{l}\text { Sufficient } \\
\text { (personnel) }\end{array} & \text { funding } & \text { and } & \text { resources } \\
\end{array}$ & $\begin{array}{l}\text { Reduction of original budget } \\
\text { Poor competence of stakeholders }\end{array}$ \\
\hline & Clear rules & $\begin{array}{l}\text { Different procurement laws (countries } \\
\text { and EU) }\end{array}$ \\
\hline & & $\begin{array}{l}\text { Obsolete legal frameworks (air rescue) } \\
\text { Administrative barriers, Unclear } \\
\text { administrative rules }\end{array}$ \\
\hline $\begin{array}{l}\text { Long-term } \\
\text { sustainability }\end{array}$ & Long-term financing as a routine & $\begin{array}{l}\text { High costs } \\
\text { No long-term financing (in particular of } \\
\text { language training) }\end{array}$ \\
\hline & $\begin{array}{l}\text { Training program accepted by staff } \\
\text { The motivation of stakeholders to } \\
\text { continue the program } \\
\text { The fun of learning a language } \\
\text { Utilization of colleagues as mentors }\end{array}$ & Poor motivation \\
\hline & Legal framework developed & Obsolete legal framework (air rescue) \\
\hline & Cooperation agreement & No cooperation agreement \\
\hline & Political support & $\begin{array}{l}\text { New political developments in the } \\
\text { relationship between Poland and } \\
\text { Germany }\end{array}$ \\
\hline & $\begin{array}{l}\text { Make language training a routine } \\
\text { Introduce language training as an element } \\
\text { of basic operational training }\end{array}$ & $\begin{array}{l}\text { Ability and willingness to continue } \\
\text { studying the language }\end{array}$ \\
\hline & Technical infrastructure & Technical communication \\
\hline & & Few cross-border emergencies \\
\hline & & Quality management \\
\hline
\end{tabular}

\section{Discussion}

Based on these two projects we can conclude that the sustainability of health systems projects is not a natural product of good project management, but must be addressed specifically and from the very beginning. Only if the leaders of the project reflect on sustainability from the first day of the project and invest effort to develop sustainers of the innovation beyond the end of the project, there is a chance that health systems research will not only result in good publications but also in long-term changes of the health care system and have an impact on the health of people.

GANI_MED has been sustainable in static and dynamic as well as in structural and functional dimensions. This is based on a number of features of the project management, which can be extracted as general rules:

- GANI_MED had a champion who was fully committed to making the research project a success.

- The champion was strongly interested in sustaining the results of the project, i.e., sustainability was a key outcome of the project from the very beginning.

- A number of partners developed from fighters to stars by gaining commitment to the content of the project. 
- Even the loss of the champion was substituted by a set of stars who safeguarded that the GANI_MED innovations have become standards of routine treatment and research at the university.

- The number of predators was limited, and their influence on long-term decisions was low.

The sustainability of InGRiP cannot be finally assessed because the project is still running. However, based on the interviews we can conclude:

- InGRiP has a champion who is a spark, i.e., a key-partner initiating the project, inspiring the partners and make research start is crucial for the success of the research project.

- The number of goiters is limited and their influence is low. Goiters who receive funds but are rather irrelevant for the sustainability of the project might be cumbersome but they do not challenge the success and sustainability.

- Sparks might leave the team of partners at the end of the project while stars remain on board. Thus, handing over leadership from sparks to stars is a major responsibility of the project management.

- The effort has to be invested to improve the willingness to change public administrations. This regularly stretches beyond the capacity of a health systems project and must be addressed by public management.

In summary, we can state that the sustainability of health systems projects is crucial if they should have a long-term impact on the health of people. For this purpose, we must understand the roles of research partners, foster innovative and committed stars and invest in strong leadership during and after the project phase. Based on the projects GANI_MED and InGRiP one can state that the sustainability of research projects requires that this objective is a key concern of all partners from the very beginning. It will not just happen but has to be planned, promoters must be fostered and roles must be clearly defined. Consequently, analyzing the different the typology of researchers and forming the team from the very beginning not only based on scientific expertise but also on characteristics like identification, long-term deployment and innovativeness will increase the sustainability of health systems research.

\section{Acknowledgments}

The publication of this work was co-financed from the funds of the Minister of Science and Higher Education in Poland, designated to research propagating activities (No. 776/PDUN/2018).

\section{References}

Brundtland, G. H. (1987). Report of the World Commission on environment and development:" Our Common Future.". United Nations.

Buck, L. E., Lassoie, J. P., \& Fernandes, E. C. (1998). Agroforestry in sustainable agricultural systems. CRC Press.

Fleßa, S. (2002). Gesundheitsreformen in Entwicklungsländern. Frankfurt a. M., Lembeck.

Fleßa, S. (2018). Systemisches Krankenhausmanagement. Walter de Gruyter GmbH \& Co KG.

Fleßa, S., John, M., \& Mahnke, J. (2011). Zwischen Vertrauen und Kontrolle. Management interdisziplinärer Forschungsverbünde-eine exemplarische Analyse. Wissenschaftsmanagement, 17, 38-43.

Fleßa, S., Thum, C., Raths, S., Fischer, T., Erdmann, P., \& Langanke, M. (2016). Systems Medicine: hype or revolution?. Personalized medicine, 13(5), 441-453. 
Haseltine, W. A. (2013). Affordable excellence: the Singapore healthcare story: how to create and manage sustainable healthcare systems. Brookings Institution Press.

Imison, C., Naylor, C., Buck, D., Curry, N., Addicott, R., \& Zollinger-Read, P. (2011). Transforming our healthcare system. London: The King's Fund.

Jonas, H. (1984). Das Prinzip Verantwortung: Versuch einer Ethik für die technologische Zivilisation. Insel-Verlag, Frankfurt am Main. English translation: The Imperative of Responsibility: In Search of an Ethics for the Technological Age, Chicago: Chicago University Press.

Kuhlman, T., \& Farrington, J. (2010). What is sustainability?. Sustainability, 2(11), 3436-3448.

Schleidgen, S., \& Marckmann, G. (2013). Alter Wein in neuen Schläuchen? Ethische Implikationen der Individualisierten Medizin. Ethik in der Medizin, 25(3), 223-231.

Schleidgen, S., Klingler, C., Bertram, T., Rogowski, W. H., \& Marckmann, G. (2013). What is personalized medicine: sharpening a vague term based on a systematic literature review. BMC medical ethics, 14(1), 55.

Thurston, H. D. (1997). Slash/mulch systems: sustainable agriculture in the tropics. Slash/mulch systems: sustainable agriculture in the tropics.

Turner, J. R. (2014). Handbook of project-based management. McGraw-hill New York, NY. 